\title{
A Comprehensive Quantitative Evaluation of New Sustainable Urbanization Level in 20 Chinese Urban Agglomerations
}

\author{
Cong $\mathrm{Xu}^{1,2}$, Shixin Wang ${ }^{1}$, Yi Zhou ${ }^{1, *}$, Litao Wang ${ }^{1}$ and Wenliang Liu ${ }^{1}$ \\ 1 Institute of Remote Sensing \& Digital Earth, Chinese Academy of Sciences, Beijing 100094, China; \\ xucong@radi.ac.cn (C.X.); wsx@irsa.ac.cn (S.W.); wanglt@irsa.ac.cn (L.W.); wlliu@irsa.ac.cn (W.L.) \\ 2 University of Chinese Academy of Sciences, Beijing 100094, China \\ * Correspondence: zhouyi@radi.ac.cn; Tel.: +86-10-6487-9460 \\ Academic Editor: Tan Yigitcanlar \\ Received: 11 December 2015; Accepted: 11 January 2016; Published: 27 January 2016
}

\begin{abstract}
On 16 March 2014, the State Council of China launched its first urbanization planning initiative dubbed "National New Urbanization Planning (2014-2020)" (NNUP). NNUP put forward 20 urban agglomerations and a sustainable development approach aiming to transform traditional Chinese urbanization to sustainable new urbanization. This study quantitatively evaluates the level of sustainability of the present new urbanization process in 20 Chinese urban agglomerations and provides some positive suggestions for the achievement of sustainable new urbanization. A three-level index system which is based on six fundamental elements in a city and a Full Permutation Polygon Synthetic Indicator evaluation method are adopted. The results show that China is undergoing a new urbanization process with a low level of sustainability and there are many problems remaining from traditional urbanization processes. There exists a polarized phenomenon in the urbanization of 20 urban agglomerations. Based on their own development patterns, the 20 urban agglomerations can be divided into seven categories. Every category has its own development characteristics. The analyses also show that waste of water resources, abuse of land resources, and air pollution are three big problems that are closely linked to traditional Chinese urbanization processes. To achieve sustainable new urbanization in China, four relevant suggestions and comments have been provided.
\end{abstract}

Keywords: sustainable new urbanization; urban agglomeration; Full Permutation Polygon Synthetic Indicator method; China

\section{Introduction}

Urbanization plays an important and indispensable role in China's development from a state of backwardness to one of prosperity [1]. However, it is well known [2] that due to the rapid and disorderly mode of development involved in traditional urbanization, a variety of social and environmental issues are increasingly arise such as: lack of resources, air and water pollution, biodiversity reductions, the proliferation of social conflicts, the distortion of residents' values, and housing shortages [3-7]. These challenges brought about by traditional urbanization have led to wide recognition of the need for effective implementation of some new development principles within the Chinese urbanization process [8].

It is within this context that on 16 March 2014 the State Council of China promulgated the "National New Urbanization Planning (2014-2020)" (NNUP). NNUP is the first urbanization planning initiative to be published and implemented by the Chinese government that aims to pull China out of the swamp of traditional urbanization, signifying China is in a key transition period shifting from 
traditional to new urbanization. The NNUP possesses two main new characteristics [1,9-13]. Firstly, it puts forward 20 urban agglomerations as the main development focus of Chinese new urbanization and, second, identifies sustainability as a guiding principle for development. Prior to this, there existed no specific urban planning for China; hence, naturally, there was no clear development focus for traditional Chinese urbanization. Through analyzing a large number of existing research papers on traditional urbanization [14-18], the authors find that most of them examine urbanization at the city level. Although some touch on urban agglomeration $[19,20]$, they emphasize a city's urbanization in isolation and ignore the urban agglomeration as a whole. In addition, the studies [19,21,22] also reveal that traditional Chinese urbanization is a spontaneous process driven by the instinctive imperatives of social and economic development, and is often not based on any scientific principle and merely seen as a simple amassment of urban elements that result in social, economic and environmental obstacles in the long term. Sustainable development [23,24], defined as "development that meets the needs of the present without compromising the ability of future generations to meet their own needs", has been proved to be an efficient and moderate method for urbanization development and is being adopted by many countries and institutions [25-29]. In this paper, the two main new characteristics of NNUP are utilized to study the sustainable new urbanization.

Generally, urbanization research methods can be grouped into two types, namely qualitative and quantitative [19]. Qualitative methods [8,14,21,30] mainly include basic theories of urbanization, shortcomings and characteristics of urbanization, and urbanization pathways. Quantitative methods, [17,31-33] on the other hand, focus on four steps: establishing a single indicator or a complex index system; choosing an appropriate assessment method; conducting a comprehensive assessment of levels of urbanization; and providing well-founded suggestions. As an intuitive and powerful auxiliary method, quantitative assessment of urbanization levels has garnered more and more attention from policymakers and scholars in recent years. Therefore, in this paper, the authors adopt the quantitative assessment method to evaluate the level of sustainable new urbanization in 20 Chinese urban agglomerations under NNUP.

\section{Two New Characteristics of NNUP}

\subsection{Putting forward 20 Urban Agglomerations as the Development Focus of Chinese New Urbanization}

The NNUP defines an urban agglomeration as "a highly congregated and widely radiant city group with optimized structure and strong complementary functions, which is developed and formed by several geographically adjacent cities following the principles of overall planning, rational layout, and collaboration". NNUP put forward 20 urban agglomerations as the development focus of Chinese new urbanization, and their spatial distribution is as shown in Figure 1. Based on NNUP and related reports [10,34], though the 20 urban agglomerations cover only $25.82 \%$ of the entire territory; however, they include $62.83 \%$ of the total population, $78.42 \%$ of the non-agricultural population, $76.87 \%$ of the fixed asset investment, $80.57 \%$ of the economy, $95.29 \%$ of the industrial production, and $86.14 \%$ of the third industry value. These data indicate that most industry, population, investment, commerce and many other socio-economic factors are concentrated in urban agglomerations. These factors have a fundamental role in current Chinese urbanization development. Moreover, it has been shown that urban agglomeration within the core of a metropolis is a modern spatial pattern and has become the principal geographic unit for countries as a basis for global comparisons, such as the international division of labor [20]. Therefore, the NNUP's choice of 20 urban agglomerations as the development focus of Chinese new urbanization is inevitable and rational. 


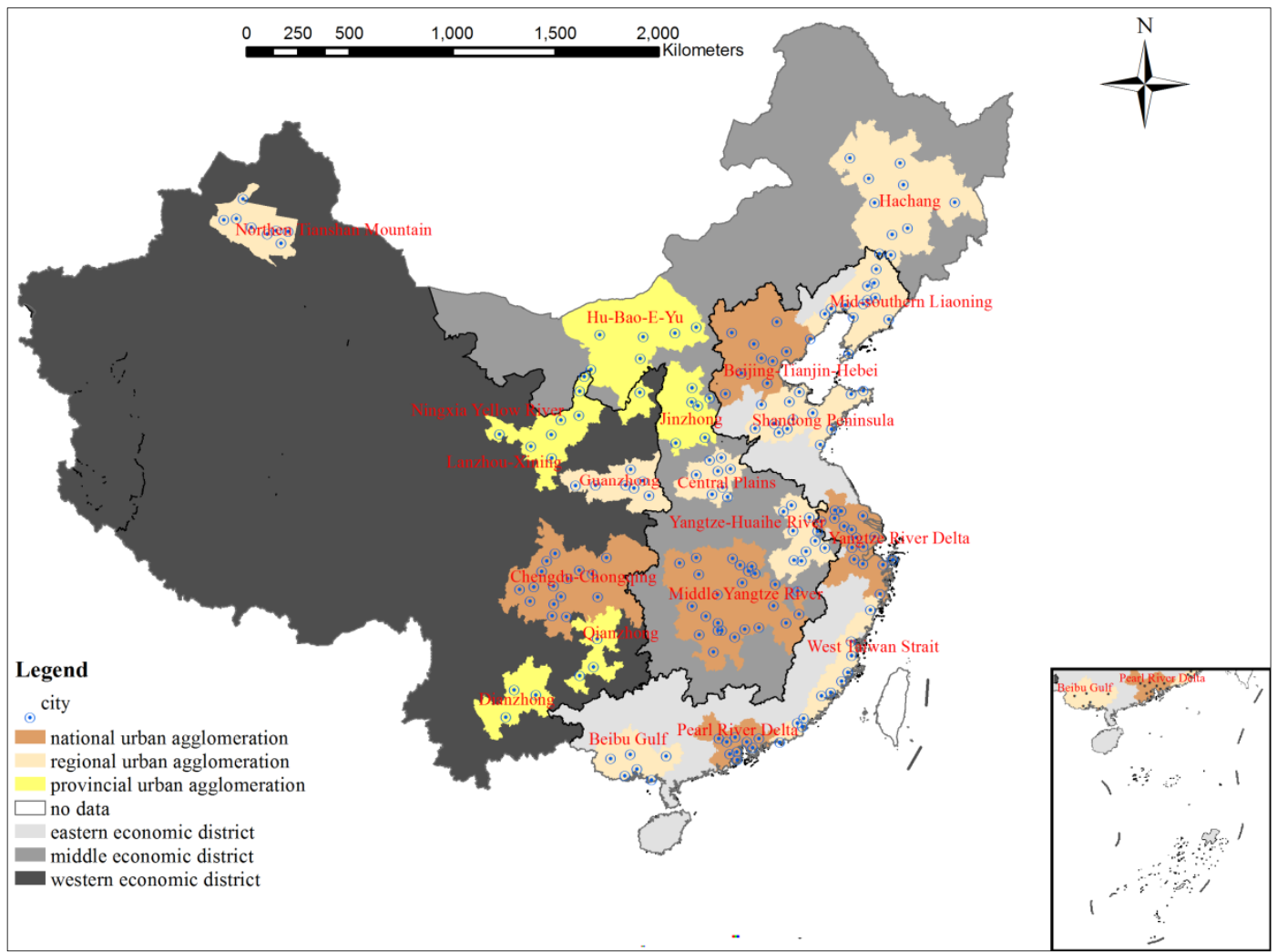

Figure 1. Spatial distribution of 20 urban agglomerations in China.

According to Figure 1, the 20 urban agglomerations cover most urbanization regions in China except for Tibet, Qinghai and other sparsely populated areas. The 20 urban agglomerations include four municipalities, 184 (65.32\% of the total in China) prefecture-level cities, 231 (62.77\%) county-level cities, and 11,787 (60.73\%) small towns. These four municipalities and 184 prefecture-level cities define this study's geographical scope (Figure 1). There are two commonly used classification methods of the 20 urban agglomerations. According to the national planning strategy, the 20 urban agglomerations can be classified into three levels [35]. Yangtze River Delta, Pearl River Delta, Beijing-Tianjin-Hebei, Middle Yangtze River, and Chengdu-Chongqing are five national urban agglomerations. They account for $9.06 \%$ of China's total territory, $35.15 \%$ of its construction land area, $43.38 \%$ of the urban population, $46.68 \%$ of GDP, and $39.11 \%$ of total fixed investment. National urban agglomerations all have national core cities (such as Shanghai in Yangtze River Delta) as the focus of development and have become powerful growth poles that drive national socio-economic development and have worldwide influence. The functional localization of national urban agglomerations is leading to their evolution in becoming world-class urban agglomerations. Mid-southern Liaoning, Shandong Peninsula, West Taiwan Strait, Hachang, Central Plains, Yangtze-Huaihe River, Guanzhong, Beibu Gulf, and Northern Tianshan Mountain comprise nine regional urban agglomerations. They account for 9.84\% of China's total territory, $25.48 \%$ of its construction land area, $28.04 \%$ of the urban population, and $31.8 \%$ of total fixed-asset investment. Regional urban agglomerations all have regional core cities such as Jinan in Shandong Peninsula that are the focus of development with sound urban systems, huge natural resource potential, and a considerable sphere of influence. The functional localization of regional urban agglomerations is driving the regional socio-economic development by enhancing the functions of central cities, promoting the division of labor and improving infrastructure. Jinzhong, Hu-Bao-E-Yu, Dianzhong, Qianzhong, Lanzhou-Xining, and Ningxia yellow river are six provincial urban agglomerations. They account for $6.92 \%$ of China's total land space, $6.39 \%$ of its construction land area, $6.55 \%$ of its urban population, $6.08 \%$ of GDP, and $6.58 \%$ of total fixed-asset investment. 
Most provincial urban agglomerations are still in the early stages of urban agglomeration development and only play an important role in the social-economic development of a relatively small area such as a province. The main function of provincial urban agglomerations is absorbing rural migrants and nurturing metropolitan areas. In addition, according to the spatial variation in development of the economy, Chinese territory can be divided into three economic districts, called the eastern economic district, middle economic district and western economic district. The 20 urban agglomerations can be divided into seven eastern urban agglomerations, six middle urban agglomerations, and seven western urban agglomerations based on the economic district an urban agglomeration lies in (as shown in Figure 1).

\subsection{Giving Chinese New Urbanization a Core and Scientific Guiding Principle-Sustainable Development}

A city is a composite of various basic elements such as people, road, buildings, commerce, and communication, etc. Chinese traditional urbanization is basically a process of simple amassment of these elements $[1,9,22]$, as shown in Figure 2. It is mentioned in Section 1 that the lack of a scientific guiding principle in traditional urbanization has caused lots of paradoxes and problems. In order to achieve sustainable new urbanization, NNUP incorporates sustainable principles into each city element (Figure 2). For instance, the economic use of water and adopting eco-friendly business environments are two forms of sustainable development with respect to water resources and economic elements. In this paper, the authors identify six fundamental elements, namely people, natural resources, natural environment, society, economy, and urban-rural relationship that make up a city $[17,32,33,36]$. As shown in Figure 3, people are the soul driving force of a city; natural resources and natural environment are two essential material bases of a city. Society, economy and the urban-rural relationship are as a result of the interaction between people, natural resources and the natural environment. According to related studies, these six elements fully characterize the urbanization development status of a city $[17,37,38]$. Figure 2 demonstrates the embodiment of sustainable development principles within these six elements in NNUP. They are described as shown below.

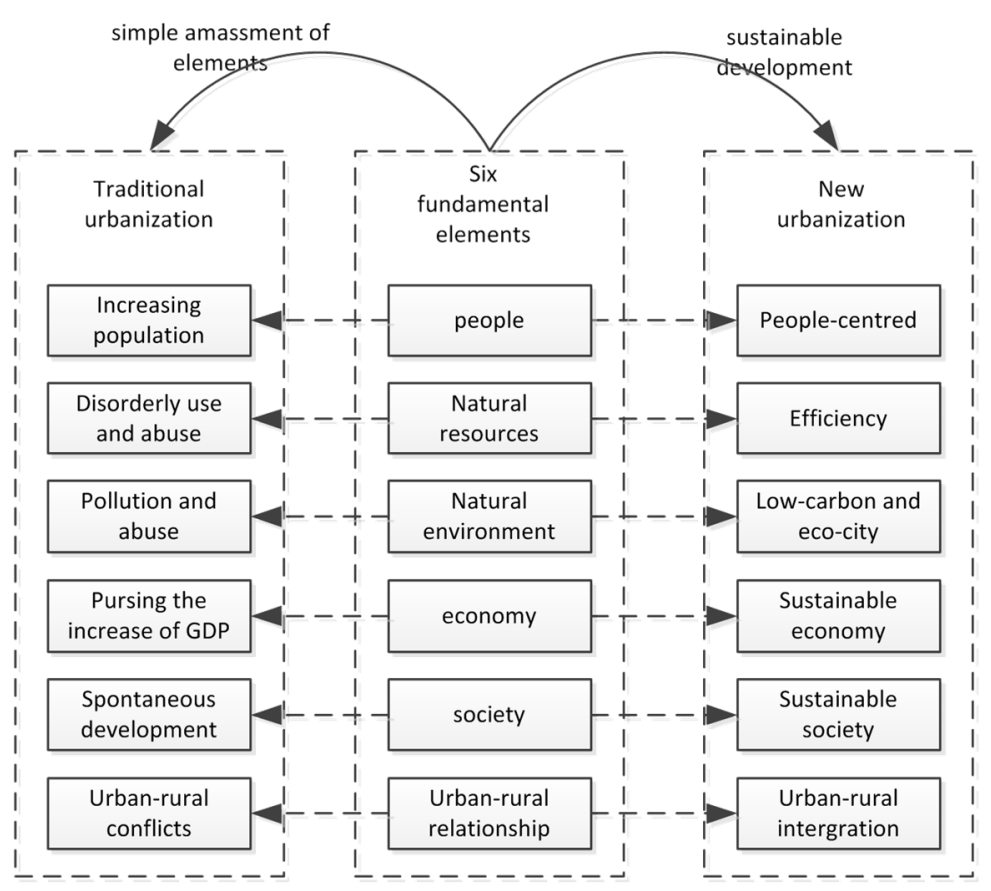

Figure 2. The difference between traditional urbanization and new urbanization. 
(1) "People-centred", contrary to "material-centred", is the core of "scientific outlook on development". It pursues free and comprehensive development of humanity, trying to fully improve the quality of life of people living in a city. NNUP strongly emphasizes three widely accepted factors that will influence the quality of life of people: namely, job, housing, and consumption level.

(2) Efficient use of natural resources could be regarded as the most intuitive reflection of sustainable development in these six elements. To achieve this, significant effort has been made in China. In NNUP, this concerns the main kinds of resources, such as water, land, electricity, and space. For some resources, NNUP even points out clear quantitative requirement, such as "area of urban construction land per capita should be strictly controlled within 100 square meters".

(3) Sustainable society is a comprehensive concept. It covers almost every aspect of people's lives. In NNUP, the current growing concerns for Chinese people, such as improving the quality of education and science, preserving the characteristics of local culture, increasing the standard of medical care, and perfecting the transportation and infrastructure, are all involved.

(4) Sustainable economy stresses that China should improve the development structure and quality of the economy while maintaining a high GDP level. In NNUP, accelerating the growth of tertiary industries, stimulating domestic demand, and reducing emissions wastage of economic outputs are considered as necessary methods to improve economic structure and quality. A sustainable economy is the only way to pull China out of the quagmire of its rather poor economic development status.

(5) Low-carbon and eco-city address sustainable development from the perspective of environmental protection, which has always been difficult because of economic growth imperatives. NNUP proposes some frequently-used solutions, such as reducing the discharge of pollution gases, increasing the ratio of city waste treatment, protecting the city greenery, etc.

(6) With the rapid rise of conflicts between urban and rural areas in recent years, the urban-rural relationship is becoming a key element of the cityscape [3]. Urban-rural integration is put forward by NNUP separately. It stresses gradually eliminating the difference in levels of development between the city and rural areas. Currently, urban and rural income and consumption disparities are designated as a first priority within the NUPP.

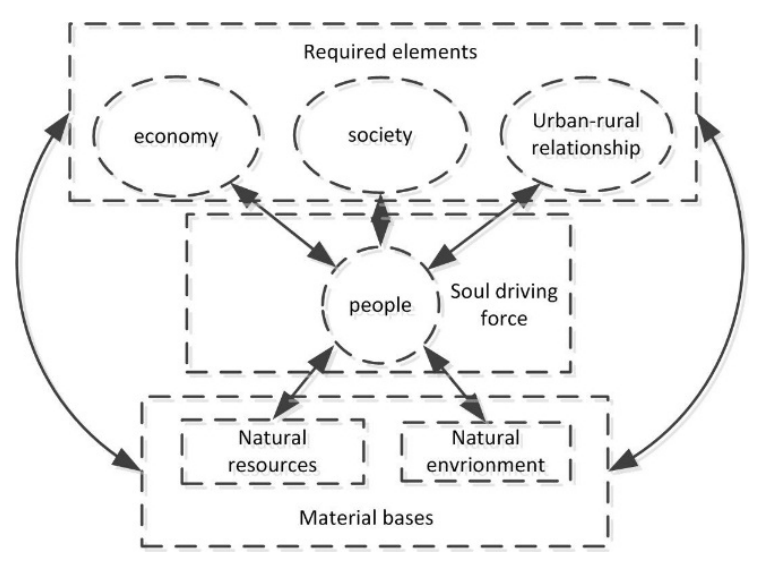

Figure 3. The relationship between six fundamental elements.

\section{Materials and Methods}

\subsection{Index System}

A complete index system is an essential tool for quantitatively assessing the level of sustainable new urbanization. Ever since the concept of new urbanization was first put forward by the 16th National Congress of Communist Party of China in 2002, numerous new urbanization index systems have been proposed $[1,10,19,39]$. However, due to lack of systematic new urbanization planning guidance, most of them cannot fully capture the contents of NNUP. For instance, most of them lack 
indicators to measure factors such as per capita building space, the network density of different pipes, annual average concentration of PM2.5, and urban-rural integration, etc. However, all the indicators mentioned above are clearly required and emphasized by NNUP. In our study, an assessment index system is developed according to the systematic analyses of NNUP described in Section 2. As shown in Table 1, this proposed assessment index system is a three-level index system, including a comprehensive indicator, first level indicators, and basic level indicators. The comprehensive indicator is the level of sustainable new urbanization which is the research focus of this paper. The six first and 25 basic level indicators are in accordance with the sustainable development principles implied in NNUP incorporating six fundamental elements. According to relevant research [20,32,38], the establishment of this index system is in accordance with the principles of scientificity, measurability, hierarchy, accessibility and completeness. Details of definitions and calculation of the index system are shown in the Appendix.

Table 1. Three level index system of new urbanization used in this paper.

\begin{tabular}{|c|c|c|}
\hline \multirow{7}{*}{$\begin{array}{c}\text { Comprehensive } \\
\text { indicator-sustainable new } \\
\text { urbanization level }\end{array}$} & First Level Indicators & Basic Level Indicators \\
\hline & Comfort of life (C) & $\begin{array}{l}\text { C1 The registered urban unemployment rate } \\
\text { C2 Per capita building space of urban household } \\
\text { C3 The proportion of urban per capita consumption } \\
\text { expenditure and urban per capita disposable income }\end{array}$ \\
\hline & Development efficiency (D) & $\begin{array}{l}\text { D1 Daily water consumption per capita } \\
\text { D2 Electricity consumption per unit of GDP } \\
\text { D3 Area of urban construction land per capita } \\
\text { D4 Density of water supply and drainage pipelines in } \\
\text { built district } \\
\text { D5 Density of road network in built district }\end{array}$ \\
\hline & Environment protection (E) & $\begin{array}{l}\text { E1 Ratio of waste water centralized treated of } \\
\text { sewage work } \\
\text { E2 Ratio of consumption wastes treated } \\
\text { E3 Green coverage rate of built district } \\
\text { E4 Annual average concentration of PM } 2.5\end{array}$ \\
\hline & Sustainable economy (Se) & $\begin{array}{l}\text { Se1 Per capita GDP } \\
\text { Se2 The average wages of workers } \\
\text { Se3 Retail sales of consumer goods per capita } \\
\text { Se4 The proportion of tertiary industrial output-value }\end{array}$ \\
\hline & Sustainable society (Ss) & $\begin{array}{l}\text { Ss1 The proportion of public financial expenditure on } \\
\text { science and technology } \\
\text { Ss2 The proportion of public financial expenditure on } \\
\text { education } \\
\text { Ss3 Collections of public libraries per } 100 \text { Persons } \\
\text { Ss4 Number of public transportation vehicles per } \\
\text { 10,000 population } \\
\text { Ss } 5 \text { Number of beds of hospitals and health centers per } \\
10,000 \text { population } \\
\text { Ss6 Water coverage rate } \\
\text { Ss7 Gas coverage rate }\end{array}$ \\
\hline & Urban-rural integration (U) & $\begin{array}{l}\text { U1 Urban-rural income ratio } \\
\text { U2 Urban-rural consumption ratio }\end{array}$ \\
\hline
\end{tabular}

\subsection{Data Sources}

The data utilized in this study can be divided into three categories: statistical data, urban plan data, and environmental data. The statistical data are derived from "China Urban Construction Statistical Yearbook, 2012" [40], "China City Statistical Yearbook, 2013" [41], and "China Statistical Yearbook for Regional Economy, 2013" [42]. The urban plan data are collected from each city's statistical bulletin as per the year 2012. The environmental data (PM2.5) are obtained from Socioeconomic Data and Applications Center (SEDAC) of National Aeronautics and Space Administration (NASA) [43]. These data are assimilated in MATLAB ${ }^{\circledR}$ platform to generate indicator values. Details of data sources of the index system are shown in the Appendix. 


\subsection{A Full Permutation Polygon Synthetic Indicator Method}

Selecting a suitable evaluation method is an important task after establishing a comprehensive index system. It is worth mentioning that when using urban agglomerations as a study object, the standard of choosing a suitable evaluation method is different from using cites as the study object. In simple terms, for a single city, an evaluation method only needs to combine all the indicator values into a synthetic value. However, for an urban agglomeration, an evaluation method further needs to be able to combine all the synthetic values of cities into a more comprehensive value. Because of this and considering the principles of the most commonly used evaluation methods, such as principal component analysis (PCA), entropy method, and analytic hierarchy process (AHP) etc., the authors find that they are all not capable of completing a full evaluation of urban agglomerations alone. For instance, if we use an entropy method to conduct the evaluation, the score of comprehensive indicators of every city can be obtained easily. However, the entropy method is unable to combine all the scores of cities contained in an urban agglomeration into a synthetic value, thus supplementary methods such as an averaging method are needed. Undoubtedly, this discontinuity in the evaluation method will weaken the credibility of the final result. In this paper, A Full Permutation Polygon Synthetic Indicator method (FPPSI) is adopted. The biggest advantage of FPPSI is that it can conduct the calculation in an iterative manner which can well solve the problem of discontinuity. Moreover, previous studies [38,44,45] also show that it can alter the traditional additive approach to combining indicators by using a multi-dimensional approach that better reflects the integrative system principle that the whole is more than the sum of its parts. At the same time, sufficient credibility and reasonability have also been shown. The principles of FPPSI are as follows:

Suppose there are $n$ indicators, an equilateral $n$-sided polygon is created based on the upper limits of each of $n$ indicators. The radius at each vertex is defined using a normalized value of 1.0. Then, an irregular $n$-sided polygon is created by the normalized actual values of each of $n$ indicators. Thus, there are aggregately $(n-1) ! / 2$ arrangements of this irregular $n$-sided polygon. The synthetic indicator is defined as the mean of area of all these irregular $n$-sided polygons to the area of the equilateral $n$-sided polygon.

The standardization process can be described as follows:

$$
F(x)=a \frac{x+b}{x+c}, a \neq 0, x \geqslant 0
$$

where $\mathrm{F}(x)$ meets the following conditions:

$$
\left.F(x)\right|_{x=L}=-1,\left.F(x)\right|_{x=T}=0,\left.F(x)\right|_{x=U}=+1
$$

where $\mathrm{U}, \mathrm{L}$, and $\mathrm{T}$ represent the upper limit, the lower limit and the threshold of parameter $\mathrm{X}$, respectively. In this paper, $\mathrm{U}, \mathrm{L}, \mathrm{T}$ represent the $\max (\operatorname{mini})$ value, mini (max) value, and mean value of positive (negative) indicator, respectively. Then

$$
\mathrm{F}(\mathrm{x})=\frac{(U-L)(x-T)}{(U+L-2 T) x+U T+L T-2 L U}
$$

For indicator $i$, the normalized value $S_{\mathrm{i}}$ is:

$$
S_{i}=\frac{\left(U_{i}-L_{i}\right)\left(\mathrm{x}-T_{i}\right)}{\left(U_{i}+L_{i}-2 T_{i}\right) x+U_{i} T_{i}+L_{i} T_{i}-2 U_{i} L_{i}}
$$

As shown in Figure 4, an outer equilateral n-sided polygon can be formed by $n$ indicators with the $n$ vertices representing $S_{i}=1$ and the central point representing $S_{i}=-1$. An inner equilateral $n$-sided polygon that lies between the outer polygon and the center of the polygon represents the threshold values of indicators, where $S_{i}=0$. Inside the inner polygon, the standardized indicator values are negative and outside the inner polygon, the standardized indicator values are positive. 


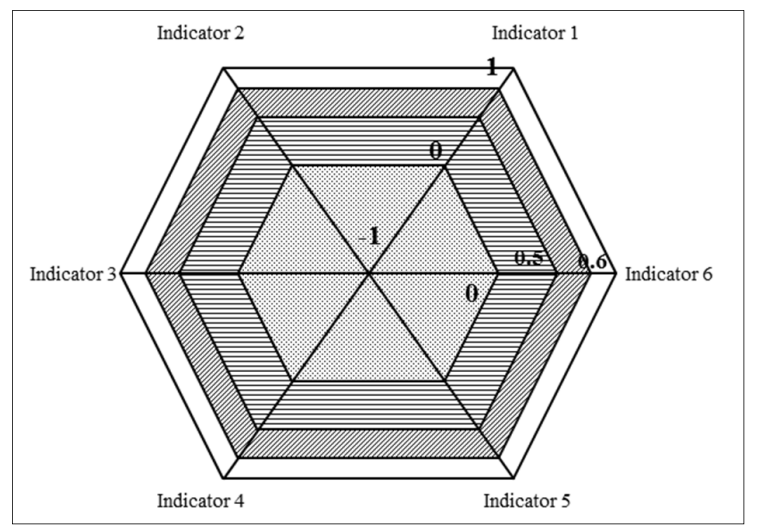

Figure 4. An example of Full Permutation Polygon Synthetic Indicator method.

There are $n \times(n-1) ! / 2=n ! / 2$ triangles created from $(n-1) ! / 2$ arrangements of irregular $n$-sided polygon. The sum area is:

$$
\left(0.5 \sin \left(\frac{\pi}{n}\right) \sum_{i \neq j}\left(s_{i}+1\right)\left(s_{j}+1\right)\right) \times \frac{n !}{2} \times \frac{2}{n(n-1)}
$$

The area of outer polygon can be calculated as $0.5 \times 4 \times n$. So, the value of FPPSI can be obtained by the following ratio:

$$
\mathrm{S}=\frac{\sum_{i \neq j}^{i, j}\left(S_{i}+1\right)\left(S_{j}+1\right)}{2 n(n-1)}
$$

where $S$ is the value of the synthetic indicator.

\section{Results}

\subsection{Analyses Based on Comprehensive Indicator}

According to Table 2, Yangtze River Delta is the urban agglomeration with the highest level of sustainable new urbanization and Ningxia yellow river is the urban agglomeration with the lowest level of sustainable new urbanization. Pearl River Delta and Qianzhong are second from the top and bottom, respectively. All 20 urban agglomerations scored a value below 0.5 implying that, in China in 2012, low levels of sustainability were achieved. Low Max/Min and CV values (Table 3) indicate that the development disparities among the 20 urban agglomerations are small.

Table 2. Ranking results of 20 urban agglomerations based on the scores of the comprehensive indicator.

\begin{tabular}{ccccc}
\hline Rank & Agglomeration Name & $\begin{array}{c}\text { Score of Comprehensive } \\
\text { Indicator }\end{array}$ & Level & District \\
\hline 1 & Yangtze River Delta & 0.489 & National & Eastern \\
2 & Pearl River Delta & 0.457 & National & Eastern \\
3 & Shandong Peninsula & 0.447 & Regional & Eastern \\
4 & Beijing-Tianjin-Hebei & 0.439 & National & Eastern \\
5 & West Taiwan Strait & 0.425 & Regional & Eastern \\
6 & Mid-southern Liaoning & 0.419 & Regional & Eastern \\
7 & Jinzhong & 0.403 & Provincial & Middle \\
8 & Northern Tianshan Mountain & 0.402 & Regional & Middle \\
9 & Middle Yangtze River & 0.400 & National & Middle \\
10 & Hu-Bao-E-Yu & 0.400 & Provincial & Middle \\
11 & Dianzhong & 0.397 & Provincial & Western \\
12 & Yangtze-Huaihe River & 0.395 & Regional & Middle \\
\hline
\end{tabular}


Table 2. Cont.

\begin{tabular}{ccccc}
\hline Rank & Agglomeration Name & $\begin{array}{c}\text { Score of Comprehensive } \\
\text { Indicator }\end{array}$ & Level & District \\
\hline 13 & Hachang & 0.381 & Regional & Middle \\
14 & Beibu Gulf & 0.374 & Regional & Eastern \\
15 & Central Plains & 0.366 & Regional & Middle \\
16 & Guanzhong & 0.359 & Regional & Western \\
17 & Lanzhou-Xining & 0.357 & Provincial & Western \\
18 & Chengdu-Chongqing & 0.348 & National & Western \\
19 & Qianzhong & 0.344 & Provincial & Western \\
20 & Ningxia yellow river & 0.337 & Provincial & Western \\
\hline
\end{tabular}

According to Table 3, based on the two classification results of 20 urban agglomerations, the rank of sustainable new urbanization level are national urban agglomerations $>$ regional urban agglomerations > provincial urban agglomerations and eastern urban agglomerations > middle urban agglomerations > western urban agglomerations. Further analyses of Mean values show that the development disparity among eastern, middle and western urban agglomerations is bigger than that among national, regional and provincial urban agglomerations. Max/Min values indicate that there are slightly larger score differences in national urban agglomerations and eastern urban agglomerations. As shown in Table 3, Chengdu-Chongqing (rank 18) and Beibu Gulf (rank 14) is far below Yangtze River Delta (rank 1). The CV values are generally lower than 0.1 , except for national urban agglomerations which score 0.128. This implies that though all six types of urban agglomerations show weak score variability, and there is stronger score variability in national urban agglomerations when comparing with others. As shown in Table 2, the five national urban agglomerations vary for numbers 1, 2, 4, 9, and 18.

Table 3. Basic statistics of the comprehensive indicator based on all 20 urban agglomerations and two classification results.

\begin{tabular}{cccccccc}
\hline & All & NUA & RUA & PUA & EUA & MUA & WUA \\
\hline Mean & 0.397 & 0.427 & 0.396 & 0.373 & 0.436 & 0.392 & 0.357 \\
Max/Min & 1.451 & 1.406 & 1.244 & 1.197 & 1.306 & 1.102 & 1.178 \\
CV & 0.102 & 0.128 & 0.074 & 0.081 & 0.082 & 0.035 & 0.059 \\
\hline
\end{tabular}

Note: $C V$, coefficient of variation, a value of $<0.1$ indicates weak variability, $0.1-1.0$ indicates moderate variability, $>1$ indicates strong variability; All, 20 urban agglomerations; NUA, national urban agglomerations; RUA, regional urban agglomerations; PUA, provincial urban agglomerations; EUA, eastern urban agglomerations; MUA, middle urban agglomerations; WUA, western urban agglomerations.

\subsection{Analyses Based on Six First Level Indicators}

\subsubsection{Development of Six First Level Indicators}

According to Table 4, the ranking of six first level indicators is sustainable society $>$ comfort of life $>$ development efficiency $>$ urban-rural integration $>$ environment protection $>$ sustainable economy. The mean score for sustainable society is higher compared to other indicators which present little difference. This indicates that, in the past few decades, the Chinese government has an obvious national policy inclination towards the development of a sustainable society. On the other hand, environmental protection and a sustainable economy perform poorly with sustainable economy scoring the lowest. This implies, to some extent, better social development is achieved at the cost of sustainable development of the environment and economy. This development irregularity reveals an obvious deficiency in traditional urbanization. In addition, the general low scores of mean values, Max/Min values, and CV values (Table 4) indicate that, in each first level indicator, the developmental difference and variation among the 20 urban agglomerations are small. Compared with others, the indicator for urban-rural integration shows the biggest developmental difference and variation among the 20 urban agglomerations. 
Table 4. Basic statistics of six first level indicators of 20 urban agglomerations.

\begin{tabular}{cccc}
\hline Six First Level Indicators & Mean & Max/Min & CV \\
\hline Comfort of life & 0.393 & 1.571 & 0.147 \\
Development efficiency & 0.391 & 1.468 & 0.086 \\
Environment protection & 0.381 & 1.534 & 0.115 \\
Sustainable economy & 0.377 & 1.576 & 0.138 \\
Sustainable society & 0.439 & 1.716 & 0.159 \\
Urban-rural integration & 0.390 & 2.082 & 0.209 \\
\hline
\end{tabular}

\subsubsection{Development of 20 Urban Agglomerations for Six First Level Indicators}

According to Section 4.2.1, considering that the score differences of the 20 urban agglomerations in each first level indicator are too small to conduct more analyses, the authors adopt a normalization method, called Z-score, to amplify the differences. The Z-score normalization formula is

$$
\mathrm{Z}=\left(x_{i}-\bar{x}\right) / \mathrm{s}
$$

where $x_{i}$ is the raw score in each first level indicator to be standardized; $\bar{x}$ is the mean of 20 urban agglomerations; $s$ is the standard deviation of the indicator. According to relevant research [46,47], a decision criterion based on the value of $Z$ is shown in Table 5 . The $Z$ scores of 20 urban agglomerations in six first level indicators are shown in Table 6.

Table 5. A decision criterion of $Z$ value.

\begin{tabular}{ccc}
\hline The Score of $\boldsymbol{Z}$ & Level & Qualitative Evaluation \\
\hline$>1$ & I & excellently \\
$0 \sim 1$ & II & well \\
$-1 \sim 0$ & III & poorly \\
$<-1$ & IV & Very poorly \\
\hline
\end{tabular}

Table 6. $Z$ scores of 20 urban agglomerations for six first level indicators.

\begin{tabular}{ccccccc}
\hline Agglomeration Name & C & D & E & Se & Ss & U \\
\hline Yangtze River Delta & 1.654 & 1.087 & 0.645 & 2.229 & 2.049 & 1.647 \\
Pearl River Delta & -0.213 & -0.008 & 0.857 & 1.987 & 1.842 & 1.212 \\
Shandong Peninsula & 1.287 & 0.685 & 0.802 & 0.628 & 1.300 & -0.267 \\
Beijing-Tianjin-Hebei & 0.587 & 0.603 & -0.669 & 1.153 & 1.408 & 0.055 \\
West Taiwan Strait & 0.599 & 0.494 & 0.848 & 0.384 & 0.415 & 0.356 \\
Mid-southern Liaoning & -0.536 & 1.417 & 0.667 & 0.090 & 0.306 & 0.614 \\
Jinzhong & 1.020 & 0.460 & -0.097 & -0.302 & -0.036 & -0.552 \\
Northern Tianshan Mountain & -0.995 & -1.151 & 0.942 & -0.639 & 0.169 & 2.727 \\
Middle Yangtze River & 0.106 & 0.215 & 0.598 & -0.577 & -0.090 & 0.358 \\
Hu-Bao-E-Yu & -0.886 & 1.259 & 0.725 & 1.259 & -0.629 & -0.109 \\
Dianzhong & 1.074 & -0.216 & 1.743 & 0.201 & -0.791 & -0.833 \\
Yangtze-Huaihe River & -0.595 & 0.349 & -0.034 & -0.407 & 0.448 & -0.649 \\
Hachang & -1.083 & 0.291 & -0.655 & -0.097 & -0.388 & 0.420 \\
Beibu Gulf & 2.075 & -0.630 & -0.181 & -0.936 & -0.634 & -1.105 \\
Central Plains & -0.115 & -0.850 & -1.879 & -0.731 & -0.440 & 0.037 \\
Guanzhong & -0.249 & 0.478 & -0.410 & -1.205 & -0.865 & -1.183 \\
Lanzhou-Xining & -1.029 & -0.941 & -1.819 & -0.378 & -0.390 & -0.835 \\
Chengdu-Chongqing & -0.557 & 0.380 & -1.419 & -1.230 & -1.154 & -0.605 \\
Qianzhong & -0.989 & -1.172 & -1.066 & -0.590 & -1.092 & -1.169 \\
Ningxia yellow river & -1.156 & -2.749 & 0.403 & -0.839 & -1.428 & -0.118 \\
\hline
\end{tabular}


Based on Tables 5 and 6 we calculate the distribution frequencies of $Z$ scores of six first level indicators at the I, II, III, and IV level for every urban agglomeration. According to which level the highest distribution frequency belongs to, Figure 5 is established. It shows that Yangtze River Delta and Pearl River Delta possess higher levels of development for most first level indicators while Chengdu-Chongqing, Qianzhong, and Ningxia yellow river show large development deficiencies for most first level indicators. This implies that, in China, there exists a polarized phenomenon in the urbanization development of urban agglomerations. Further analyzing the $\mathrm{Z}$ score distribution frequency in I, II, III, and IV level for every urban agglomeration, it is found that the 20 urban agglomerations display other significant score distribution patterns (as shown in Table 7). According to this, we divide them into seven categories (Table 7). Urban agglomerations in each category display similar development patterns. Based on Tables 6 and 7 the development details of every urban agglomeration can be summarized as follows.

\begin{tabular}{|c|c|c|c|}
\hline \multirow{2}{*}{ I } & II & III & IV \\
& Shandong Peninsula & Jinzhong & \\
& Hu-Bao-E-Yu & Chengdu-Chongqing \\
Yangtze River Delta & Deijing-Tianjin-Hebei & Yangtze-Huaihe River & Qianzhong \\
Pearl River Delta & West Taiwan Strait & Hachang & Ningxia yellow river \\
& Mid-southern Liaoning & Beibu Gulf & \\
& Northern Tianshan Mountain & Central Plains & \\
& Middle Yangtze River & Guanzhong & \\
& & Lanzhou-Xining & \\
& & &
\end{tabular}

Figure 5. The clustering result of 20 urban agglomerations based on which level (I, II, III, and IV) the highest distribution frequency of $Z$ scores of the six first level indicators for each urban agglomeration belongs to.

Table 7. The result of dividing 20 urbanization agglomerations into seven categories based on the $Z$ score distribution regularities of six first level indicators for each urban agglomeration at four levels (I, II, III, and IV).

\begin{tabular}{|c|c|c|c|c|c|c|}
\hline \multirow[t]{2}{*}{ Category } & \multirow[t]{2}{*}{ Agglomeration Name } & \multicolumn{4}{|c|}{$\begin{array}{l}\text { Z Score Distribution } \\
\text { Frequency of Six First Level } \\
\text { Indicators in Four Levels }\end{array}$} & \multirow{2}{*}{$\begin{array}{c}\text { Z Score Distribution Regularity } \\
\text { Based on the Z Score } \\
\text { Distribution Frequency }\end{array}$} \\
\hline & & I & II & III & IV & \\
\hline \multirow{2}{*}{1} & Yangtze River Delta & 5 & 1 & 0 & 0 & \multirow{2}{*}{$\begin{array}{l}\text { all six first level indicators } \\
\text { perform excellently or well }\end{array}$} \\
\hline & West Taiwan Strait & 0 & 6 & 0 & 0 & \\
\hline \multirow{2}{*}{2} & Lanzhou-Xining & 0 & 0 & 4 & 2 & \multirow{2}{*}{$\begin{array}{l}\text { all six first level indicators } \\
\text { perform poorly or very poorly }\end{array}$} \\
\hline & Qianzhong & 0 & 0 & 2 & 4 & \\
\hline \multirow{2}{*}{3} & Middle Yangtze River & 0 & 4 & 2 & 0 & \multirow{2}{*}{$\begin{array}{l}\text { some indicators perform well } \\
\text { and the others perform poorly }\end{array}$} \\
\hline & Yangtze-Huaihe River & 0 & 2 & 4 & 0 & \\
\hline \multirow{4}{*}{4} & Pearl River Delta & 3 & 1 & 2 & 0 & \multirow{4}{*}{$\begin{array}{l}\text { one or two first level indicators } \\
\text { perform poorly; the others } \\
\text { perform well or excellently }\end{array}$} \\
\hline & Shandong Peninsula & 2 & 3 & 1 & 0 & \\
\hline & Beijing-Tianjin-Hebei & 2 & 3 & 1 & 0 & \\
\hline & Mid-southern Liaoning & 1 & 4 & 1 & 0 & \\
\hline \multirow{5}{*}{5} & Hachang & 0 & 2 & 3 & 1 & \multirow{5}{*}{$\begin{array}{l}\text { one or two first level indicators } \\
\text { perform well; the others perform } \\
\text { poorly or very poorly }\end{array}$} \\
\hline & Central Plains & 0 & 1 & 4 & 1 & \\
\hline & Guanzhong & 0 & 1 & 3 & 2 & \\
\hline & Chengdu-Chongqing & 0 & 1 & 2 & 3 & \\
\hline & Ningxia yellow river & 0 & 1 & 2 & 3 & \\
\hline \multirow{2}{*}{6} & \multirow{2}{*}{$\begin{array}{c}\text { Beibu Gulf } \\
\text { Northern Tianshan } \\
\text { Mountain }\end{array}$} & 1 & 0 & 4 & 1 & \multirow{2}{*}{$\begin{array}{l}\text { one first level indicator performs } \\
\text { excellently; one performs very } \\
\text { poorly }\end{array}$} \\
\hline & & 1 & 2 & 2 & 1 & \\
\hline \multirow{3}{*}{7} & Jinzhong & 1 & 1 & 4 & 0 & \multirow{3}{*}{$\begin{array}{l}\text { no first level indicators perform } \\
\text { very poorly; one or two perform } \\
\text { excellently; most perform poorly }\end{array}$} \\
\hline & Hu-Bao-E-Yu & 2 & 1 & 3 & 0 & \\
\hline & Dianzhong & 2 & 1 & 3 & 0 & \\
\hline
\end{tabular}


Category 1: Five of six first level indicators of Yangtze River Delta perform excellently (level I) and one indicator performs well (level II). All six first level indicators of West Taiwan Strait perform well. This means that Yangtze River Delta and West Taiwan Strait are two balanced and good development urban agglomerations which is partly due to their abundant natural resources, developed transportation network, and excellent location (along the coast).

Category 2: All six first level indicators of Lanzhou-Xining and Qianzhong score less than 0 and some are even less than -1 , which means that Lanzhou-Xining and Qianzhong are two urban agglomerations that perform poorly (level III) or very poorly (level IV) for all six first level indicators. Different from urban agglomerations in category 1, these two urban agglomerations are located in fragile ecological areas coupled with traffic problems and poor natural resources. In this context, it can be predicted that it is a long and difficult task for the local governments to fully improve their level of sustainable new urbanization.

Category 3: Middle Yangtze River and Yangtze-Huaihe River are two urban agglomerations that some first level indicators of them perform well and the others perform badly, no indicators performing excellently or very badly. It means that they are two neutral development urban agglomerations. There possess no distinct development superiorities or deficiencies. They can try to develop one or two indicators to a high level in the future while ensuring the good development of other indicators.

Category 4: Pearl River Delta, Shandong Peninsula, Beijing-Tianjin-Hebei and Mid-southern Liaoning are four urban agglomerations that have one or two first level indicators performing badly and the others performing well or excellently. It indicates that these four urban agglomerations all have one or two development deficiencies. To be specific, Pearl River Delta has a low quality of life and low development efficiency which results from the influx of a large floating population and the rapid expansion of the city's size in the past few decades. The urban-rural difference of Shandong Peninsula is large which is caused by a government policy inclination towards improving urban incomes and consumption. The air pollution problems generated in the short term make Beijing-Tianjin-Hebei perform badly in environmental protection. Mid-southern Liaoning has low quality of life which is caused by the existence of lots of shanty towns and a large number of immigrants.

Category 5: Contrary to the urban agglomerations in category 4, Hachang, Central Plains, Guanzhong, Chengdu-Chongqing and Ningxia yellow river are five urban agglomerations that have one or two first level indicators performing well and the others performing badly or very badly. It indicates that though the overall development of these five urban agglomerations is low, they still have certain development superiorities. To be specific, Hachang has good development efficiency and low urban-rural difference. Central Plains' urban-rural difference is small. The development efficiency of Guanzhong and Chengdu-Chongqing is good. Ningxia yellow river does a good job in environmental protection. Similar to the urban agglomerations in category 2, the sustainable new urbanization development of these five urban agglomerations is restricted for various reasons. For instance, Central Plains is a main grain-producing area in China; thus, the development of other industries has been remarkably restrained. Likewise, as Ningxia yellow river is situated inland with a dry climate and scarce precipitation, the lack of water resources has always been a limiting factor for its development.

Category 6: Beibu Gulf and Northern Tianshan Mountain all have one first level indicator performing excellently and one indicator performing very badly. It indicates that they are examples of two polarized urban agglomerations. To be specific, Beibu Gulf possesses the best quality of life and a rather big urban-rural difference. Northern Tianshan Mountain does a very good job in urban-rural integration while has very low development efficiency. A high level of sustainable new urbanization is achieved by the harmonious development of different indicators. So, it is necessary for them to narrow the difference in levels of development among different indicators in the future.

Category 7: A main characteristic of Jinzhong, Hu-Bao-E-Yu, and Dianzhong is that no first level indicators perform very badly but of them perform badly. This is mainly due to the fact that these three urban agglomerations are all located in central and western China which has relatively low 
economic development, making it difficult to develop other aspects in a city. Nonetheless, despite the bad location, the mild climate and fewer immigrants, Jinzhong and Dianzhong possess a very high quality of life and $\mathrm{Hu}-\mathrm{Bao}-\mathrm{E}-\mathrm{Yu}$ possesses good development efficiency.

\subsection{Analysis Based on Basic Level Indicators}

According to Table 8, water coverage rate (Ss6) and gas coverage rate (Ss7) are two basic level indicators that have developed far better than the others. It implies that the development of a sustainable society is mainly based on the development of social infrastructure. Compared with the other two level indicators, basic level indicators have obvious bigger Max/Min values (most are more than 4) and CV values (most are more than 0.4 ). It indicates that the 20 urban agglomerations display distinct development disparities for basic level indicators, especially for the indicators of density of water supply and drainage pipelines in built-up districts, collections of public libraries per 100 persons, and gas coverage rate which has a rather big Max/Min value (more than 100).

Table 8. Basic statistics for 25 basic level indicators of 20 urban agglomerations.

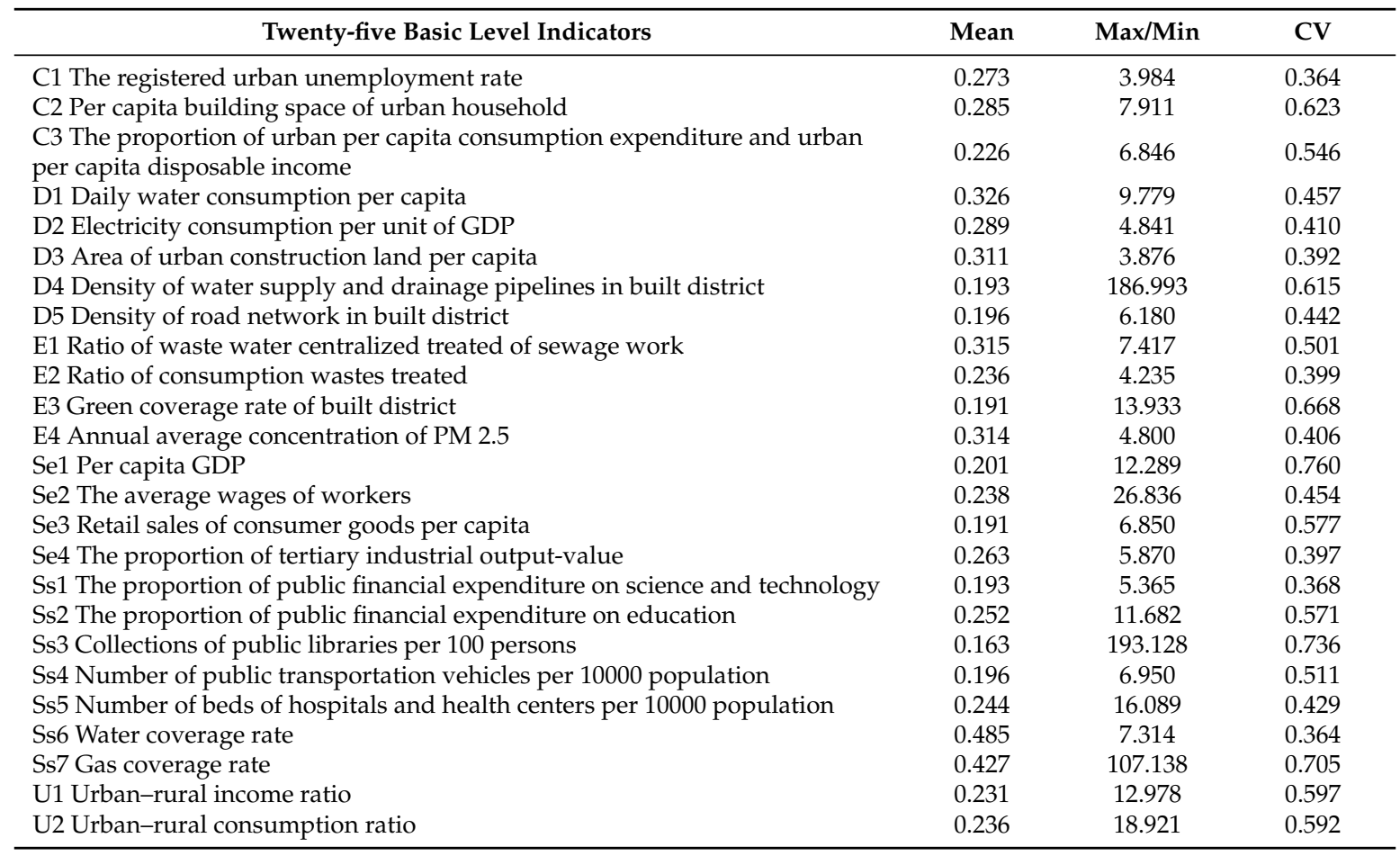

Table 9 shows that the correlation coefficients between comprehensive indicator, the six first level indicators and most basic indicators are all positive and significant. It reveals that the higher the level of sustainable new urbanization is, the higher the level of sustainable development elements within an urban agglomeration will generally present. However, there are several basic level indicators negatively correlated to the comprehensive indicator. These include daily water consumption per capita (D1), area of urban construction land per capita (D3), and annual average concentration of PM 2.5 (E4). It shows that waste of water resources, abuse of land resources, and air pollution are three big problems that are closely linked to traditional Chinese urbanization processes. Therefore, it is necessary to take some appropriate and timely measures to prevent these problems from worsening in order to achieve sustainable new urbanization. There are also some basic indicators showing low or no significant positive correlation with the comprehensive indicator. These include per capita building space of urban household (C2), the proportion of urban per capita consumption expenditure and urban per capita disposable income (C3), electricity consumption per unit of GDP (D2), ratio of Consumption Wastes Treated (E2), the proportion of tertiary industrial output-value (Se4), the proportion of public 
financial expenditure on education (Ss2), and number of Beds of Hospitals and Health Centers per 10000 population (Ss2). This implies that it is also necessary for government policy to focus more on the city elements of housing, consumption levels, electricity, waste treatment, industrial structures, education and health.

Table 9. Correlation test between sustainable new urbanization and first basic level indicators.

\begin{tabular}{cccccccc}
\hline \multicolumn{2}{c}{ P.C. with CI } & \multicolumn{2}{c}{ P.C. with CI } & \multicolumn{2}{c}{ P.C. with CI } & \multicolumn{2}{c}{ P.C. with CI } \\
\hline C & $0.529^{*}$ & D4 & $0.823^{* *}$ & Se1 & $0.823^{* *}$ & Ss4 & $0.611^{* *}$ \\
C1 & $0.642^{* *}$ & D5 & $0.850^{* *}$ & Se2 & $0.588^{* *}$ & Ss5 & 0.180 \\
C2 & 0.420 & E & $0.561^{*}$ & Se3 & $0.837^{* *}$ & Ss6 & $0.843^{* *}$ \\
C3 & 0.135 & E1 & $0.646^{* *}$ & Se4 & 0.196 & Ss7 & $0.805^{* *}$ \\
D & $0.608^{* *}$ & E2 & $0.207^{* *}$ & Ss & $0.937^{* *}$ & U & $0.575^{* *}$ \\
D1 & -0.128 & E3 & $0.723^{* *}$ & Ss1 & $0.752^{* *}$ & U1 & $0.573^{* *}$ \\
D2 & 0.245 & E4 & -0.124 & Ss2 & 0.164 & U2 & $0.536^{*}$ \\
D3 & -0.314 & Se & $0.860^{* *}$ & Ss3 & $0.722^{* *}$ & & \\
\hline
\end{tabular}

Note: P.C., Pearson product-moment correlation coefficient; CI, comprehensive indicator; C1, C2, C3, D1, D2, D3, D4, D5, E1, E2, E3, E4, Se1, Se2, Se3, Se4, Ss1, Ss2, Ss3, Ss4, Ss5, Ss6, Ss7, U1, and U2, code of 25 basic level indicators (as shown in Table 1); *, Significant at the 0.05 level (1-tailed); **, Significant at the 0.01 level (2-tailed).

\section{Discussions and Suggestions}

\subsection{Reducing the Development Disparity of Cities Contained within an Urban Agglomeration}

It is clearly that the level of sustainable new urbanization of an urban agglomeration directly depends on the development levels of all cities contained within it. According to Figure 6, it can be seen that most basic indicators score less than 0.6 which has resulted in the lower scores for the six first level indicators and the low overall rating of the level of sustainable new urbanization in China. This illustrates that for each basic indicator, each urban agglomeration contains poorly developed cities. With the increase in the number of low level cities, the level of sustainable new urbanization of an urban agglomeration will deteriorate. Examples include cities like Beijing, Tianjin and Shijiazhuang in the urban agglomeration of Beijing-Tianjin-Hebei whose annual average concentration of PM 2.5 is higher than other cities resulting in providing poor environmental protection. Likewise, cities of Jinan and Yantai have a bigger urban-rural income and consumption ratio than other cities in the urban agglomeration of Shandong Peninsula, thus damaging the urban-rural integration. Therefore, it is necessary to reduce the development disparity of cities contained within an urban agglomeration.

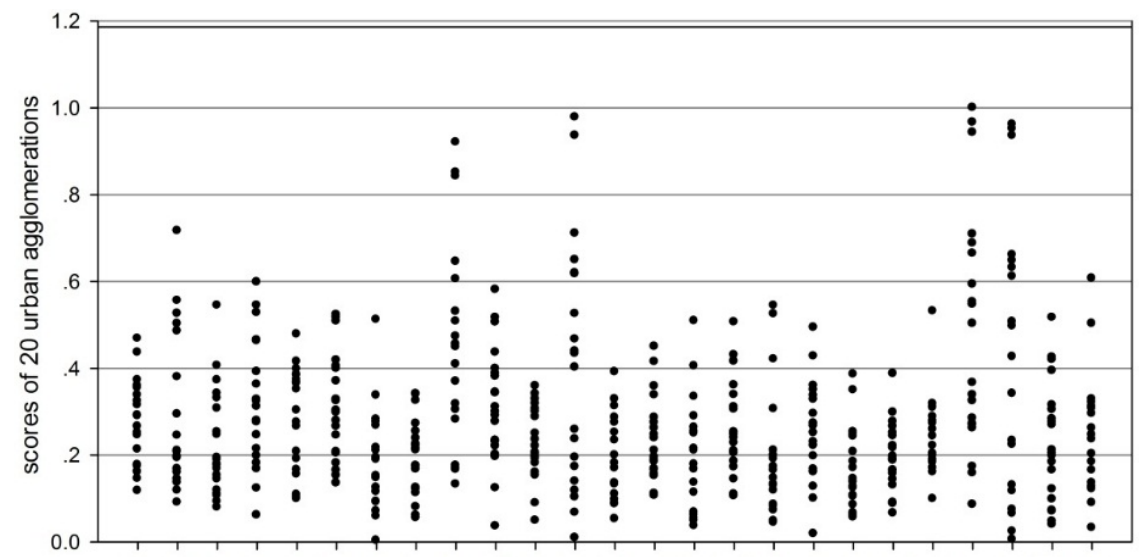

C1 C2 C3 D1 D2 D3 D4 D5 E1 E2 E3 E4 Se1 Se2 Se3 Se4 Ss1 Ss2 Ss3 Ss4 Ss5 Ss6 Ss7 U1 U2 code of 25 basic level indicators

Figure 6. Score distribution of 20 urban agglomerations for 25 basic level indicators. 


\subsection{Strengthening Cooperation among Different Types of Urban Agglomerations}

It is shown in Figure 7 that national urban agglomerations rank top for 18 of the 25 basic level indicators and eastern urban agglomerations rank top for one in 20 of the 25 basic level indicators. The two ranking results, $\mathrm{N}>\mathrm{R}>\mathrm{P}$ and $\mathrm{E}>\mathrm{M}>\mathrm{W}$, occur at an overwhelming frequency (more than $0.55)$ among all ranking results. It means national and eastern urban agglomerations dominate in almost every aspect of sustainable new urbanization development whilst provincial and western urban agglomerations lag far behind. Using the more advanced to bring along the less advanced is a development philosophy proposed in NNUP. Therefore, strengthening the communication between different types of urban agglomeration can help in the transfer of development experience and skills and help improve development efficiency.

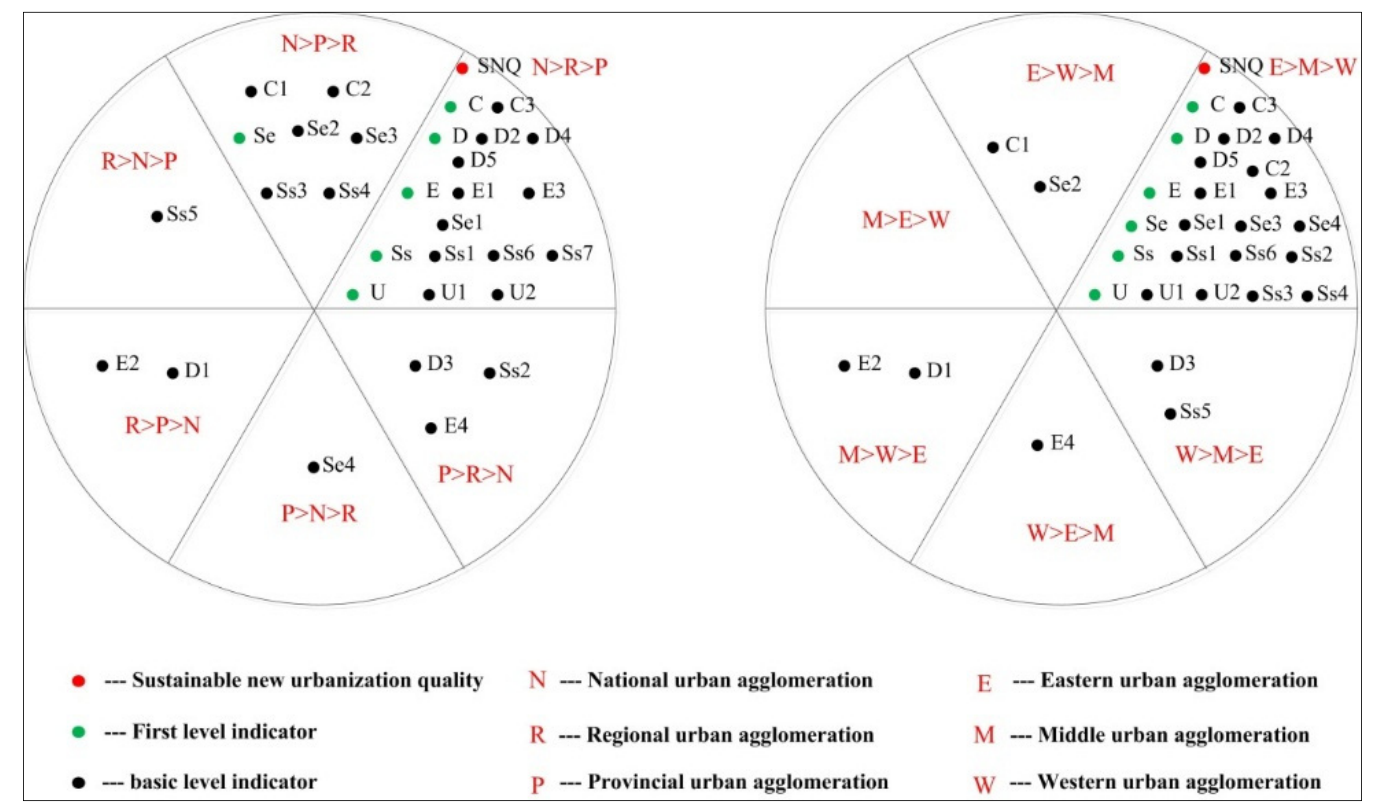

Figure 7. Results of ranking the scores of three level indicators in national, regional, and provincial urban agglomerations (left) and eastern, middle, and western urban agglomerations (right).

\subsection{Measures to Improve Low Sustainable Development Level Indicators}

Some common and implicit problems of sustainable new urbanization development in China and every urban agglomeration are pointed out in this paper. These include lack of environmental protection, low levels of economic development, natural resource abuse, and insufficient domestic demand, etc. High levels of sustainable new urbanization are reflected by sustainable and balanced development of various elements in a city. Sacrificing one element in order to achieve another one is unscientific and not agrees with the nature of sustainable development. Traditional urbanization has resulted in an abnormal urbanization development status in China and will greatly hinder the achievement of sustainable new urbanization. Hence, adopting key mitigation measures is a critical step in transitioning from traditional to sustainable new urbanization. Several specific measures are shown as follows:

(1) Setting up examination and evaluation mechanisms of environmental protection and ecological civilization. Then, imputing the mechanisms into the evaluation system of new urbanization development and establishing sound assessment and reward and punishment measures.

(2) Maintaining reasonable control of the total energy consumption, accelerating the development of clean coal technology, promoting the production of natural gas, developing nuclear energy safely and efficiently, and speeding up the exploration of renewable energy, e.g. wind energy and solar energy. 
(3) Making fundamental changes to the economic growth mode and ensuring the efficient use of natural resources to achieve the goal of getting the biggest possible economic and social benefits using the least possible resources and with minimal environmental impact.

(4) Increasing people's incomes, eliminating excessive income gaps, and enhancing the social security system to stimulate household consumption and boost domestic demand.

\subsection{Guaranteeing the Implementation of Policies in NNUP}

Implementation of specific measures and policies is the only way to turn a systematic theory analysis into reality. NNUP has set up a detailed planning implementation process, involving cooperation of all levels of government. However, the implementation of specific policies is a long, difficult and easily neglected process. In order to fully guarantee the implementation of NNUP, sufficient additional supporting measures need to be taken. In this paper, we propose three specific measures. First, strengthen the coordination between the governments and organizations at all levels and ensure regular supervision and measurement of progress. Governments and organizations at all levels should improve the implementation of NNUP by building a technical city management cadre. Second, it is necessary to select different regions or cities to carry out trial work and, according to the development realities in different urban agglomerations, to establish a diversity of local policies to ensure the smooth implementation of NNUP. Third, establishing and improving a unified evaluation index system to measure levels of sustainable new urbanization and standardize statistical calibers, statistical standards, and statistical systems in different regions.

\section{Conclusions}

In this paper, two main new characteristics of NNUP are used to evaluate the level of sustainability of new urbanization processes in 20 Chinese urban agglomerations. Six fundamental elements of a city are used to establish a three-level index system, and a Full Permutation Polygon Synthetic Indicator method is utilized to complete the evaluation. The results give a better understanding of how to achieve sustainable new urbanization. Sustainable development, as the core guiding principle of NNUP, will play a vital role in China's future as it transitions from the traditional mode of urbanization to a sustainable new one. It can be predicted that numerous sustainability studies about NNUP will surface soon. Taking 20 urban agglomerations as the study object is a new and challenging feat for Chinese urbanization research. Little relevant research could be referred to in the process. This paper has undertaken some exploratory studies on which evaluation method to choose and how to analyze the results.

NNUP is a short-term planning initiative whose main focus is on the transformation of urbanization development concepts. Due to the large number of problems associated with traditional urbanization, it can be predicted that in the future there will be more new urbanization planning approaches coming to the fore. So, it is necessary to take each step along the way cautiously. The creation of a sustainable new urbanization development environment is projected to be a long-term and arduous task, requiring the concerted efforts of managers, policy makers, and the general public.

Acknowledgments: This research was funded by the key state science and technology project (Grant No.00-Y30B14-9001-14/16-1) and the National Natural Science Foundation of China (Grant No.41201441). We would give sincerely thanks to our friends Chege, George Watene; Yang, Yu; Lin, Ding and Cheng, Jing for their valuable comments and suggestions, which provide great help in improving our manuscript.

Author Contributions: Cong Xu performed the experiments and wrote the paper; Shixin Wang and Yi Zhou conceived and designed the experiments; Litao Wang and Wenliang Liu contributed analysis tools. All authors read and approved the final manuscript.

Conflicts of Interest: The authors declare no conflict of interest. 


\section{Appendix}

Table A1. Definitions, calculation, and data source of basic level indicators used in this paper.

\begin{tabular}{|c|c|c|c|}
\hline Basic Level Indicators & Definitions and Calculation & Unit & Data Source \\
\hline $\mathrm{C} 1^{1}$ & $\begin{array}{l}\text { (Registered urban unemployment people)/(Total } \\
\text { registered urban unemployment and employment } \\
\text { people) }\end{array}$ & $\%$ & $\mathrm{RE}^{*}[42]$ \\
\hline $\mathrm{C} 2^{1}$ & $\begin{array}{l}\text { (Total building space of urban household)/(The number } \\
\text { of total urban population) }\end{array}$ & $\mathrm{m}^{2}$ & $\mathrm{RE} *[42]$ \\
\hline $\mathrm{C} 3^{2}$ & $\begin{array}{l}\text { (Urban per capita consumption expenditure })^{1} /(\text { Urban } \\
\text { per capita disposable income })^{1}\end{array}$ & $\%$ & $\mathrm{RE} *[42]$ \\
\hline $\mathrm{D} 1^{1}$ & $\begin{array}{l}\text { (Total amount of water supply)/(The number of total } \\
\text { urban population) }\end{array}$ & $\mathrm{L}$ & UC [40] \\
\hline $\mathrm{D} 2^{2}$ & (Total electricity consumption) $)^{1} /(\text { Total GDP })^{1}$ & KWh & $\mathrm{CSY} *[41]$ \\
\hline D3 ${ }^{2}$ & $\begin{array}{l}\text { (Total area of urban construction land })^{1} /(\text { The number of } \\
\text { total urban population })^{1}\end{array}$ & $\mathrm{~m}^{2}$ & $\mathrm{UC} *[40]$ \\
\hline $\mathrm{D} 4^{2}$ & $\begin{array}{l}\text { (Total length of water supply and drainage pipelines in } \\
\left.\text { built district) }{ }^{1 /} / \text { (Total area of built district) }\right)^{1}\end{array}$ & $\mathrm{Km}^{-1}$ & UC [40] \\
\hline D5 ${ }^{2}$ & $\begin{array}{l}\text { (Total length of road network in built district) })^{1} /(\text { Total } \\
\text { area of built district) })^{1}\end{array}$ & $\mathrm{Km}^{-1}$ & UC [40] \\
\hline $\mathrm{E} 1^{1}$ & $\begin{array}{l}\text { (Total amount of waste water centralized treated of } \\
\text { sewage work)/( Total amount of waste water) }\end{array}$ & $\%$ & $\mathrm{UC} *[40]$ \\
\hline $\mathrm{E} 2^{1}$ & $\begin{array}{l}\text { (Total volume of consumption wastes treated)/(Total } \\
\text { volume of consumption wastes) }\end{array}$ & $\%$ & $\mathrm{UC} *[40]$ \\
\hline $\mathrm{E} 3^{1}$ & $\begin{array}{l}\text { (Total area of green coverage in built district)/(Total area } \\
\text { of built district) }\end{array}$ & $\%$ & UC [40] \\
\hline $\mathrm{E} 4^{1}$ & $\begin{array}{l}\text { (The sum of daily average concentration of PM 2.5)/(The } \\
\text { number of valid days) }\end{array}$ & $\mu \mathrm{g} / \mathrm{m}^{3}$ & SEDAC of NASA \\
\hline Se $1^{1}$ & (Total GDP)/( The number of total urban population) & Yuan & CSY \\
\hline $\operatorname{Se} 2{ }^{1}$ & $\begin{array}{l}\text { (Total paid wages of workers)/(The average number of } \\
\text { workers) }\end{array}$ & Yuan & $\mathrm{RE}^{*}[42]$ \\
\hline $\mathrm{Se} 3^{2}$ & $\begin{array}{l}\text { (Total retail sales of consumer goods) })^{1} /(\text { The number of } \\
\text { total urban population) }{ }^{1}\end{array}$ & Yuan & $\mathrm{CSY}^{*}[41]$ \\
\hline Se $4^{1}$ & (Total output-value of tertiary industry)/(Total GDP) & $\%$ & CSY [41] \\
\hline Ss $1^{2}$ & $\begin{array}{l}\text { (Public financial expenditure on science and technology) } \\
1 /\left(\text { Total public financial expenditure) }{ }^{1}\right.\end{array}$ & $\%$ & CSY [41] \\
\hline Ss $2^{2}$ & $\begin{array}{l}\text { (Public financial expenditure on education })^{1} / \text { (Total } \\
\text { public financial expenditure) })^{1}\end{array}$ & $\%$ & CSY [41] \\
\hline Ss $3^{1}$ & $\begin{array}{l}\text { (Total collections of public libraries } \times 100) /(\text { The number } \\
\text { of total urban population) }\end{array}$ & Piece & CSY [41] \\
\hline Ss $4^{1}$ & $\begin{array}{l}\text { (Total number of public transportation vehicles } \times \\
10000) /(\text { The number of total urban population) }\end{array}$ & Vehicle & $\mathrm{CSY} *[41]$ \\
\hline Ss $5^{2}$ & $\begin{array}{l}\text { (Total number of beds of hospitals and health centers } \times \\
10000)^{1} /(\text { The number of total urban population })^{1}\end{array}$ & Bed & CSY [41] \\
\hline Ss $6^{1}$ & $\begin{array}{l}\text { (The number of urban population with water)/(The } \\
\text { number of total urban population) }\end{array}$ & $\%$ & UC [40] \\
\hline Ss $7^{1}$ & $\begin{array}{l}\text { (The number of urban population using gas)/(The } \\
\text { number of total urban population) }\end{array}$ & $\%$ & UC [40] \\
\hline $\mathrm{U} 1^{2}$ & $\begin{array}{l}\text { (Urban per capita disposable income) })^{1 /} \text { (Rural per capita } \\
\text { net income) })^{1}\end{array}$ & $\%$ & $\mathrm{RE} *[42]$ \\
\hline $\mathrm{U} 2^{2}$ & $\begin{array}{l}\text { (Urban per capita consumption expenditure) })^{1} /(\text { Rural } \\
\text { per capita consumption expenditure })^{1}\end{array}$ & $\%$ & $\mathrm{RE}^{*}[42]$ \\
\hline
\end{tabular}

Note: ${ }^{1}$, data of these indicators can be directly obtained; ${ }^{2}$, data of these indicators cannot be directly obtained and need to be calculated through other indicators whose data can be directly obtained; RE, "China Statistical Yearbook for Regional Economy, 2013" [42]; UC, "China Urban Construction Statistical Yearbook, 2012" [40]; CSY, "China City Statistical Yearbook, 2013" [41]; SEDAC of NASA, Socioeconomic Data and Applications Center of National Aeronautics and Space Administration; * , need data supplement from 2012 statistical bulletin of certain city whose data is missing in corresponding statistical yearbook; C1, C2, C3, D1, D2, D3, D4, D5, E1, E2, E3, E4, Se1, Se2, Se3, Se4, Ss1, Ss2, Ss3, Ss4, Ss5, Ss6, Ss7, U1, and U2, code of 25 basic level indicators (as shown in Table 1). 


\section{References}

1. Zhang, Z.B.; Liu, R.; Huang, K. Annual Report on the Healthy Development of China's New Urbanization; Press of Social Science: Beijing, China, 2014.

2. Shen, L.; Zhou, J. Examining the effectiveness of indicators for guiding sustainable urbanization in China. Habitat Int. 2014, 44, 111-120. [CrossRef]

3. Ann, T.; Wu, Y.Z.; Zheng, B.B.; Zhang, X.L.; Shen, L.Y. Identifying risk factors of urban-rural conflict in urbanization: A case of China. Habitat Int. 2014, 44, 177-185.

4. Chen, J.; Guo, F.; Wu, Y. One decade of urban housing reform in China: Urban housing price dynamics and the role of migration and urbanization, 1995-2005. Habitat Int. 2011, 35, 1-8. [CrossRef]

5. Gong, P.; Song, L.; Elizabeth, J.C.; Jiang, Q.W.; Wu, J.Y.; Justin, V.R. Urbanisation and health in China. Lancet 2012, 379, 843-852. [CrossRef]

6. He, C.Y.; Liu, Z.F.; Tian, J.; Qun, M. Urban expansion dynamics and natural habitat loss in China: A multiscale landscape perspective. Glob. Change Biol. 2014, 20, 2886-2902. [CrossRef] [PubMed]

7. Tosics, I. The Chinese urban development dilemma: Heritage and green areas as victims of rapid urbanization. Mazowsze Stud. Reg. 2012, 9, 87-100.

8. Gu, C.L.; Wu, L.Y.; Ian, C. Progress in research on Chinese urbanization. Front. Archit. Res. 2012, 1, $101-149$.

9. Fang, C. Strategic direction of the transformation of China's new urbanization development. Resour. Environ. Dev. 2014, 2, 18-26.

10. Fang, C. Report on New Urbanization Development of China; Press of Social Science: Beijing, China, 2014.

11. $\mathrm{Xu}, \mathrm{H}$. National New Urbanization Planning-Expert Interpretation. Available online: http://www.banyuetan.org/chcontent/zx/yw/2014317/96663.html (accessed on 15 January 2016). (In Chinese)

12. Yao, S.-M.; Zhang, P.-Y.; Yu, C.; Li, G.-Y.; Wang, C.-X. The theory and practice of new urbanization in China. Sci. Geogr. Sini. 2014, 34, 641-647.

13. Yu, L. Low carbon eco-city: New approach for Chinese urbanisation. Habitat Int. 2014, 44, 102-110. [CrossRef]

14. Chai, H.-H.; Gu, H.-Y.; Zhang, Q.-H. A literature review on the existing research of China's rural urbanization. J. Econ. Geogr. 2009, 4, 654-661.

15. Gu, C.-L.; Pang, H.-F. Evolution of Chinese urbanization spaces: Kernel spatial approach. Sci. Geogr. Sin. 2009, 29, 10-14.

16. Li, Y.K.; Lu, Y.J.; Young Hoon, K.; Dong, S. Developing a city-level multi-project management information system for Chinese urbanization. Int. J. Proj. Manag. 2015, 33, 510-527. [CrossRef]

17. Yu, T.; Zhang, J.X.; Luo, X.L. The Research on Urbanization Quality of County-Level Cities in Eastern Developed Area of China-A Case Study of Changshu City. Urban Stud. 2010, 11, 7-12.

18. Ji, Y.H.; Li, J.W. International comparison of Chinese urbanization. Urban Stud. 2004, 3, 1-10.

19. Zhou, D.; Xu, J.C.; Wang, L.; Lin, Z.L. Assessing urbanization quality using structure and function analyses: A case study of the urban agglomeration around Hangzhou Bay (UAHB), China. Habitat Int. 2015, 49, 165-176. [CrossRef]

20. Liu, H.M. Comprehensive carrying capacity of the urban agglomeration in the Yangtze River Delta, China. Habitat Int. 2012, 36, 462-470. [CrossRef]

21. Shen, J.F. Chinese urbanization and urban policy. China Rev. 2000, 1, 455-480.

22. Niu, W.Y. Essential Points of Strategic Design of Chinese New-Approach Urbanization. Bull. Chin. Acad. Sci. 2009, 2, 005.

23. Cash, D.W.; Clark, W.C.; Alcock, F.; Dickson, N.M.; Eckley, N.; Guston, D.H.; Jäger, J.; Mitchell, R.B. Knowledge systems for sustainable development. Proc. Natl. Acad. Sci. USA 2003, 100, 8086-8091. [CrossRef] [PubMed]

24. Hopwood, B.; Mellor, M.; O’Brien, G. Sustainable development: Mapping different approaches. Sustain. Dev. 2005, 13, 38-52. [CrossRef]

25. Costanza, R.; D’Arge, R.; de Groot, R.; Farber, S.; Grasso, M.; Hannon, B.; Limburg, K.; Naeem, S.; O’Neill, R.V.; Paruelo, J.; et al. The value of the world's ecosystem services and natural capital. Ecol. Econ. 1998, 1, 3-15. [CrossRef]

26. Diamantini, C.; Zanon, B. Planning the urban sustainable development The case of the plan for the province of Trento, Italy. Environ. Impact Assess. Rev. 2000, 20, 299-310. [CrossRef] 
27. Nations, U. Indicators of Sustainable Development: Guidelines and Methodologies, 3rd ed.; UNDESA: New York, NY, USA, 2007.

28. UN Habitat. Urban Indicator Guidelines: Better Information, Better Cities; UN Habitat: Nairobi, Kenya, 2009.

29. Bank, W. World Development Indicators: 2013; World Bank: Washington, DC, USA, 2013.

30. Gu, L.J. Low Carbon City: The New Idea of Chinese Urbanization. Future Dev. 2010, 3, $2-5$.

31. Cheng, C.J. Dynamic Quantitative Analysis on Chinese Urbanization and Growth of Service Sector. In LISS 2012; Springer: Berlin, Germany, 2013; pp. 663-670.

32. Bai, X. The Measurement Analysis and Empirical Research of China's Urbanization Process; Hohai University: Nanjing, China, 2004.

33. Fang, C.; Wang, D.L. Comprehensive measures and improvement of Chinese urbanization development quality. Geogr. Res. 2011, 11, 1931-1946.

34. Tan, R.H.; Liu, Y.L.; Liu, Y.F.; He, Q.S.; Ming, L.C.; Tang, S. Urban growth and its determinants across the Wuhan urban agglomeration, central China. Habitat Int. 2014, 44, 268-281. [CrossRef]

35. Agency, X.N. China will Build 20 Urban Agglomerations with Three Types, Focusing on the Construction of Pearl River Delta and so on Five Big Urban Agglomeration. Available online: http:/ /news.xinhuanet.com/ house/cq/2015-01-15/c_1113997434.htm (accessed on 15 January 2016). (In Chinese)

36. Wei, H.K.; Wang, Y.Q.; Su, H.J.; Guo, Y.B. A comprehensive report of Chinese urbanization quality. Rev. Econ. Res. 2013, 31, 3-32.

37. Zhao, J.J.; Chai, L.H. A novel approach for urbanization level evaluation based on information entropy principle: A case of Beijing. Phys. A Stat. Mech. Its Appl. 2015, 430, 114-125. [CrossRef]

38. Li, F.; Liu, X.S.; Wang, R.D.; Yang, W.R.; Li, D.; Zhao, D. Measurement indicators and an evaluation approach for assessing urban sustainable development: A case study for China's Jining City. Landsc. Urban Plan. 2009, 90, 134-142. [CrossRef]

39. Feng, S.L.; Huang, W.G.; Wang, J.; Wang, M.Q.; Zha, J. Low-carbon City and New-type Urbanization: Proceedings of Chinese Low-carbon City Development International Conference; Springer: Berlin, Germany, 2015.

40. Ministry of Housing and Urban-Rural Development of the People's Republic of China. China Urban Construction Statistical Yearbook; China Planning Press: Beijing, China, 2013.

41. Department of Urban Surveys of National Bureau of Statistics. China City Statistical Yearbook; China Statistics Press: Beijing, China, 2013.

42. Department of Comprehensive Statistics of National Bureau of Statistics. China Statistical Yearbook for Regional Economy; China Statistics Press: Beijing, China, 2013.

43. Socioeconomic Data and Applications Center (SEDAC) of National Aeronautics and Space Administration (NASA). Available online: http://sedac.ciesin.columbia.edu/data/set/sdei-global-annual-avg-pm2-5-20012010/data-download (accessed on 15 January 2016).

44. Gong, Y.B.; Zhang, J.G.; Liang, X.C. Water Quality Assessment of East Route Based on Entire-array-polygon Evaluation Method. China Popul. Resour. Environ. 2011, 9, 26-31.

45. Cheng, L.; Dong, J. Evalution on intensive land use of Wuhan metropolitan agglomeration based on entire-aggay-polygon evaluation model. Res. Soil Water Conserv. 2014, 1, 183-187.

46. Chen, M.X.; Huang, Y.B.; Tang, Z.P.; Lu, D.D.; Liu, H.; Ma, L. The provincial pattern of the relationship between urbanization and economic development in China. J. Geogr. Sci. 2014, 24, 33-45. [CrossRef]

47. Chen, M.X.; Liu, W.D.; Tao, X.L. Evolution and assessment on China's urbanization 1960-2010: Under-urbanization or over-urbanization? Habitat Int. 2013, 38, 25-33. [CrossRef]

(C) 2016 by the authors; licensee MDPI, Basel, Switzerland. This article is an open access article distributed under the terms and conditions of the Creative Commons by Attribution (CC-BY) license (http://creativecommons.org/licenses/by/4.0/). 